\title{
Using Ionic Liquid Modified Zeolite as a Permeable Reactive Wall to Limit Arsenic Contamination of a Freshwater Lake-Pilot Tests
}

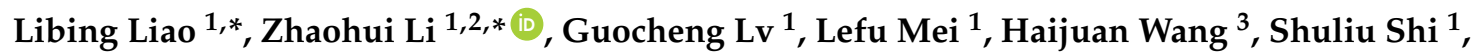 \\ Yaozu Wei ${ }^{1}$, Xiaoyu Wang ${ }^{1}$, Ping Ning ${ }^{3}$ and Yanke Wei ${ }^{1}$ \\ 1 Beijing Key Laboratory of Materials Utilization of Nonmetallic Minerals and Solid Wastes, \\ National Laboratory of Mineral Materials, School of Materials Science and Technology, \\ China University of Geosciences, Beijing 100083, China; guochenglv@cugb.edu.cn (G.L.); \\ mlf@cugb.edu.cn (L.M.); shishuliu1991@163.com (S.S.); weiyaozu1896@163.com (Y.W.); \\ 15210964175@163.com (X.W.); wei13140165707@163.com (Y.W.) \\ 2 Geosciences Department, University of Wisconsin-Parkside, Kenosha, WI 53141-2000, USA \\ 3 Faculty of Environmental Science and Engineering, Kunming University of Science and Technology, \\ Kunming 650500, China; wanghj@kmust.edu.cn (H.W.); ningping58@sina.com (P.N.) \\ * Correspondence: lbliao@cugb.edu.cn (L.L.); li@upw.edu (Z.L.); Tel.: +1-262-595-2487 (Z.L.)
}

Received: 13 March 2018; Accepted: 4 April 2018; Published: 9 April 2018

\begin{abstract}
Arsenic (As) contamination of surface water has long been a threat to human health. Extensive studies were made at the bench-scale for the removal of As from water. Commonly-used materials for the removal of As include Al and Fe hydroxides that will form complexes with As. Recently, modification of Earth materials to reverse their surface charge to positive to reduce the mobility of arsenite and arsenate also attracted great attention. In 2008, a severe As contamination was reported in the lake of Yangzonghai, Yunnan, China. Although the As concentration was maintained below $0.05 \mathrm{mg} / \mathrm{L}$ for the lake, after 28 months of restoration, the discharge of mine tailings from a nearby fertilizer plants was still one of the contributors to the As in the lake. In this study, zeolite was modified by ionic liquids and the modified materials were installed as a permeable reactive wall (PRW) to contain the As movement. Preliminary results showed more than an $80 \%$ reduction in As after surface water moved through the PWR over the six-month sampling period confirming the effectiveness of ionic liquid-modified Earth materials for environmental application.
\end{abstract}

Keywords: arsenic; ionic liquid; modification; permeable reactive wall; retardation; zeolite

\section{Introduction}

The concept of permeable reactive walls or barriers (PRWs or PRBs) was proposed in the 1990s, mainly for the removal of dissolved contaminants while allowing regular groundwater flow. The initial packing materials for PRWs were granular zero-valent iron (GZVI), due to its exceptional degradation of a variety of inorganic and organic contaminants, such as chlorinated solvents, semivolatiles, arsenic, and chromium. It is often mixed with other porous, yet inactive, ingredients, such as sand. In addition to GZVI, other materials with good hydraulic conductivity, such as surfactant-modified zeolite (SMZ), were also tested for the removal of contaminants of multiple types via sorption or degradation at a pilot scale [1]. As such, numerous studies have been conducted over the last 20 years, mostly in the formulation of the barrier materials for best performance in terms of the rate of removal and types of contaminants to be removed. These studies were mostly at the laboratory-scale, including batch and column tests. 
On a separate testing scale, pilot tests of PRWs were also conducted extensively all over the world, mainly for the unconfined aquifers with shallow groundwater table and for dissolved phases of contaminants. A case study was conducted in East Helena, Montana, USA, to treat the groundwater contaminated with arsenic, selenium, lead, cadmium and zinc. After over two years of monitoring, results indicated arsenic concentrations, initially greater than $25 \mathrm{mg} / \mathrm{L}$ upgradient of the PRB, were reduced to 2 to $<0.01 \mathrm{mg} / \mathrm{L}$ with $\sim 99 \%$ removal [2]. A full-scale case study was conducted at a contaminated site in Needham, Massachusetts, USA, with trichloroethene (TCE) as the primary contaminant at a concentration as high as $1100 \mu \mathrm{g} / \mathrm{L}$. Seven-year data from 2001 to 2007 showed TCE removal rate about $80 \%$ with the down-gradient concentration of $5 \mu \mathrm{g} / \mathrm{L}$ [3]. On the opposite side, a pilot scale funnel and gate PRW of $30 \mathrm{ft}$ long by $7 \mathrm{ft}$ deep by $5 \mathrm{ft}$ wide was installed in Colorado, USA, in 2000, to treat the groundwater contaminated with molybdenum (Mb) and uranium (U) with average concentrations of 4.8 and $1 \mathrm{mg} / \mathrm{L}$, respectively [4]. The PWR lost its function to retard the movement of Mo in less than a year. In addition, a reduced hydraulic conductivity due to calcium precipitation resulted in groundwater by passing the PRW [4].

A severe arsenic (As) contamination was reported in the lake of Yangzonghai, Yunnan, China in 2008 [5]. Between December 2008 and September 2009, four rounds of sampling were conducted to investigate the As content and its trends in concentration variation around Yangzonghai Lake in Yunnan Province, Southwestern China [6]. It was found that the arithmetic average of the As contents were $176.9,147.3,159.3$, and $161.1 \mu \mathrm{g} / \mathrm{L}$ for the lake water and 32.87, 62.41, 62.99, and $46.96 \mu \mathrm{g} / \mathrm{g}$ for the lake sediments, while the higher As concentration in the soil around the lake was $23.33 \mu \mathrm{g} / \mathrm{g}$ [6]. The As content in the lake determined in April 2010 was between 72 and $101 \mu \mathrm{g} / \mathrm{L}$, increasing as the depth increased, suggesting its sources from surface water input originating from the Phosphor fertilizer plant at the south side [7]. After 28 months of restoration, the As concentration was maintained below $0.05 \mathrm{mg} / \mathrm{L}$, a degree of $80 \%$ in comparison to that in October 2008, and the As concentration in the bottom sediments were $21.5-27.0 \mu \mathrm{g} / \mathrm{g}$ [5]. A spray of $\mathrm{FeCl}_{3}$ on the surface of the lake at a rate of $1.6-3.2 \mathrm{mg} / \mathrm{L}$ could result in As removal of $95-97 \%$ in a pilot test made of $10,000 \mathrm{~m}^{3}$ and $250,000 \mathrm{~m}^{3}$ lake water [8]. In one study, it was concluded that the iron-arsenic precipitates were highly stable in lake water [9]. In another study, the As in sediments was destabilized and the distribution and mobilization of As were affected by the redox conditions and seasonal variations [10]. As the source of the As was believed from the phosphors fertilizer plant about $0.6 \mathrm{~km}$ to the southwest of the lake, it is necessary to stop or alleviate the As input from the source to the lake.

The current study is an international collaboration project funded by the Ministry of Science and Technology of China to treat the As-contaminated water and soil collectively in a integrative way with the soil As to be removed by phytoremediation and the As in the surface runoff to the lake to be intercepted with a PRW. As most of the pilot- or full-scale PRW demonstrations were installed underground, primarily for the treatment of groundwater [11] and acid mine drainage [12], this study was the first, to the best of our knowledge, to treat a seasonal surface water for the removal of As at the pilot-scale.

\section{Materials and Methods}

\subsection{Materials}

The zeolite was obtained from Weichang, Hebei, China, with components of clinoptilolite and stibnite (see Section 3.1). The zeolite was crushed to particle sizes of 1.0 and $1.5 \mathrm{~mm}$. The ionic liquid (IL) used was 1-hexadecyl-3-methylimidazolium chloride monohydrate (HMCM), purchased from Shanghai Jiecheng Chemical Co. Ltd. (Shanghai, China).

\subsection{Lab Zeolite Modification}

Modification of zeolite by IL in the laboratory was performed using the following procedures. $20.0 \mathrm{~g}$ of zeolite was mixed with $100 \mathrm{~mL}$ of IL at concentrations of $200 \mathrm{mmol} / \mathrm{L}$ for $12 \mathrm{~h}$. The mixtures 
were centrifuged for $5 \mathrm{~min}$ at a speed of $6000 \mathrm{rpm}$. After decanting the supernatant, the zeolite was washed with two portions of deionized water before being dried naturally. The product was named as ionic liquid-modified zeolite (ILMZ).

\subsection{Batch and Column Tests for As Removal}

For batch experiments, $10 \mathrm{~mL}$ of As solutions with varying concentrations and $1 \mathrm{~g}$ of ILMZ were mixed for $24 \mathrm{~h}$. The column used had a radius of $2.5 \mathrm{~cm}$ and a length of $20 \mathrm{~cm}$, resulting in a volume of about $100 \mathrm{~cm}^{3}$. About $80 \mathrm{~g}$ of raw zeolite or ILMZ were packed into each column. The packed materials had a porosity of about 0.5 , corresponding to a pore volume (PV) of $40 \mathrm{~cm}^{3}$. The initial As (V) concentration was set at about $900 \mathrm{ppb}$, corresponding to the As concentration in the polluted water. The As-containing water was fed to the column using a peristaltic pump at a flow rate of $0.4 \mathrm{~cm}^{3} / \mathrm{min}$.

\subsection{Pilot Scale PRW Design}

The valley at the narrowest part is $2-3 \mathrm{~m}$ wide. An initial design of the PRW was to have the wells collecting water sample at multiple depths, spacing at $0.5 \mathrm{~m}$ in elevation and in spacing (Figure 1). Each well is made of $0.25 \mathrm{~cm}$ ID and $0.30 \mathrm{~cm}$ OD plastic tubes inserted into a $2.5 \mathrm{~cm}$ PVC pipe. Each well was installed as a pan lysimeter with the pan holding a volume about $1 \mathrm{~L}$ [13].

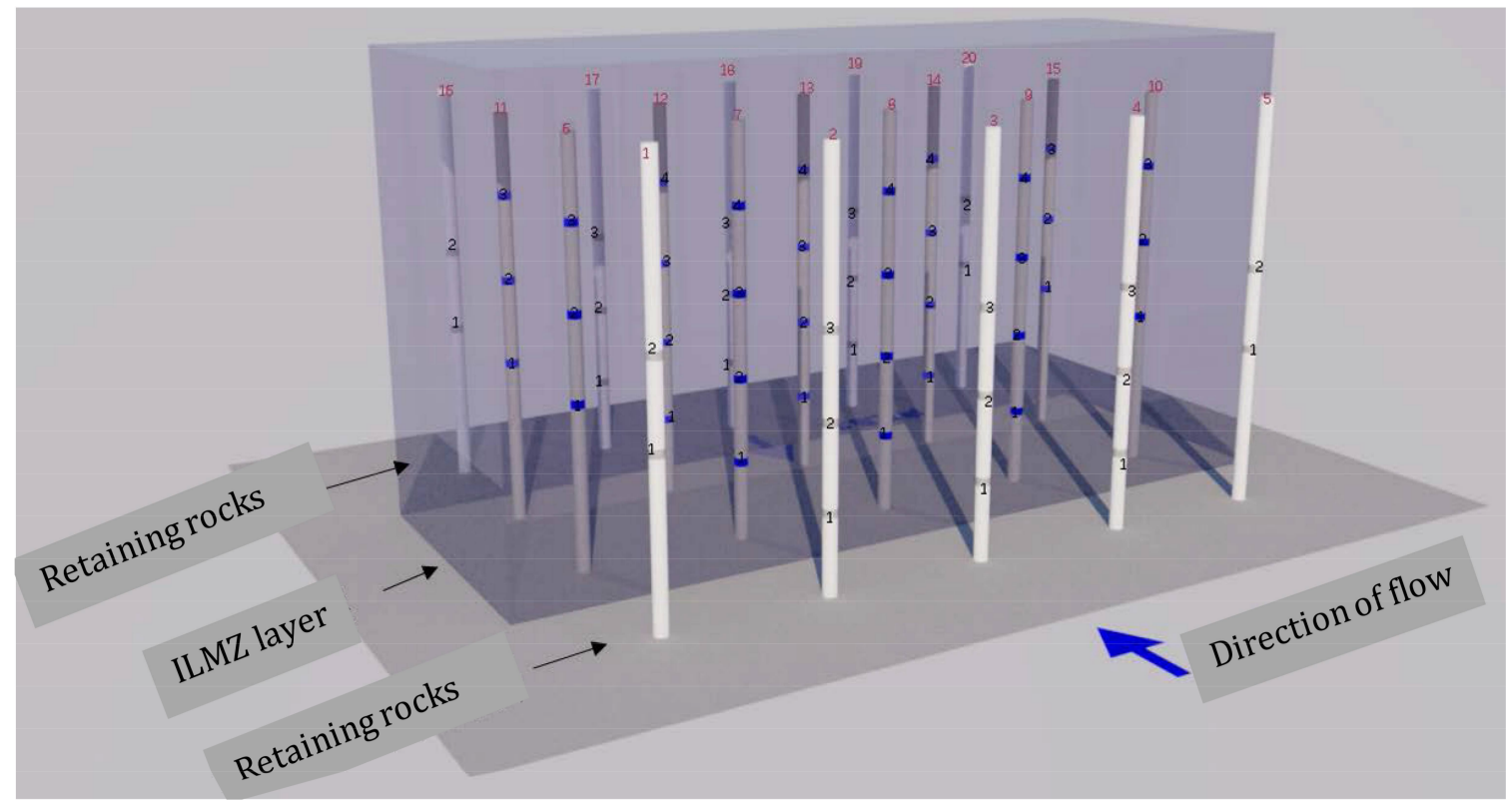

Figure 1. Schematic illustrate of the monitoring wells installed in the PRW. The numbers in black font on each well show the sampling port elevation with 1 at $0.5 \mathrm{~m}$ above the bottom. The numbers in red denote the sample wells in space.

\subsection{Field Scale ILMZ Preparation}

At the field scale, a concrete mixer (Figure $2 b$ ) was used to mix the zeolite (tan pile in foreground) with the IL (in blue containers of $50 \mathrm{~kg}$ containing $70 \%$ IL) to achieve a bilayer IL surface coverage. The amount of zeolite to IL used was at a ratio of 1 ton of zeolite to $50 \mathrm{~kg}$ of $70 \%$ IL with about $0.5 \mathrm{~m}^{3}$ of water added resulting in a solid to liquid ratio of about 2 . A total of 20 metric tons were produced over a five-day period. Overall, the amount of IL used was $3 \%$ of the zeolite weight.

\subsection{Pilot Scale PRW Installation}

The PRW was installed in a valley near Yangzonghai Lake, Yunnan Province, which is about $100 \mathrm{~km}$ southwest of Kunming (Figure 2a). The valley was dug to $1.0 \mathrm{~m}$ below the bottom surface to 
a width of $4 \mathrm{~m}$ and thickness of $2 \mathrm{~m}$. Frameworks were made to fix the location of each monitoring well. Plywood was used to enclose the space for filling the slurry mix of ILMZ. After each batch the ILMZ was transported down to the PRW using a sheet pile to slide the mixture down the river valley. After full installation, the PRW had 20 sampling wells separated by $0.5 \mathrm{~m}$ (Figure 3). Each well had 2-3 sampling depth (Figure 1).
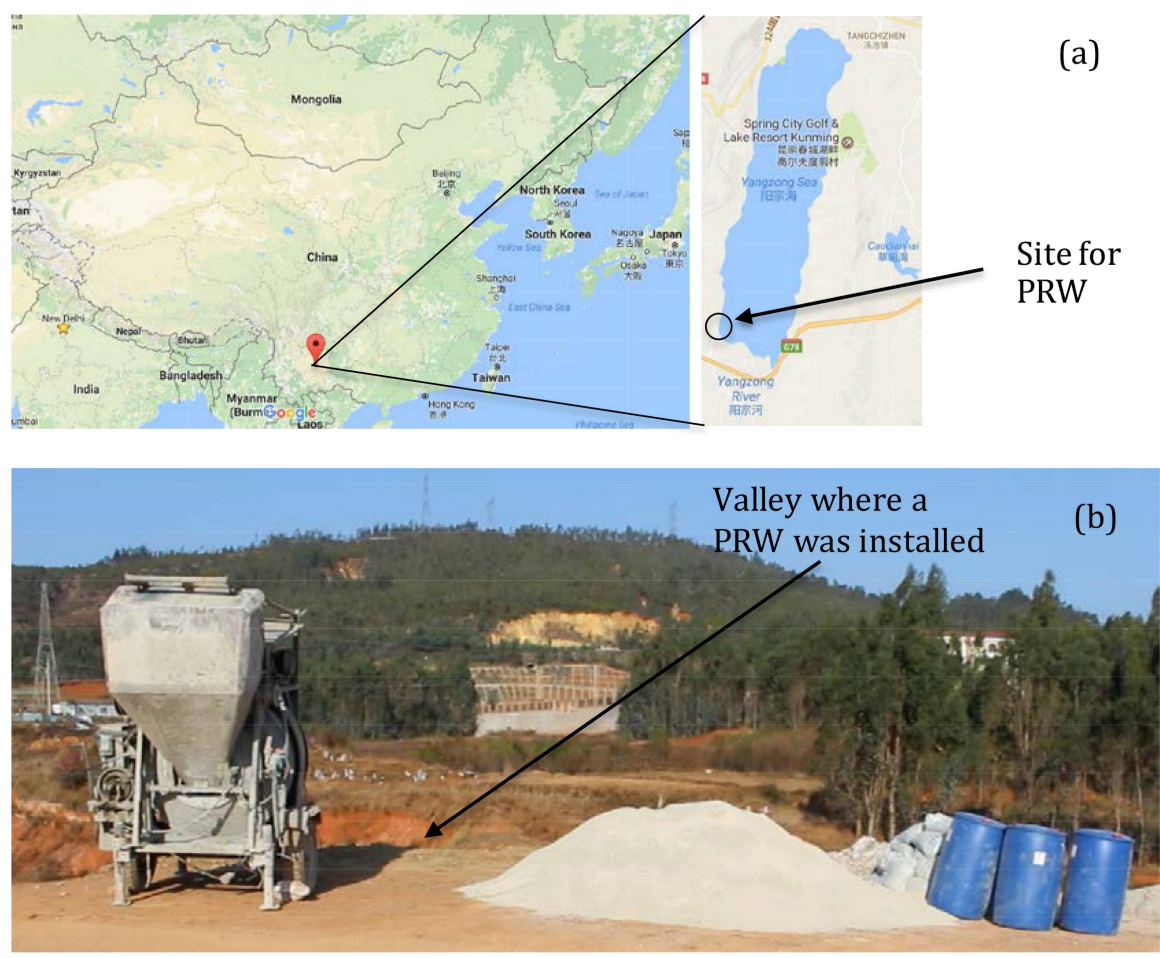

Figure 2. The location of the pilot test site (a); The ILMZ was produced on site with a concrete mixer (b). The zeolite is in foreground and the IL is in the blue drums. The bags behind the drums are unopened zeolite bags about $100 \mathrm{~kg}$ each. The valley where the PRW was installed is in the middle of the picture behind the mixer.
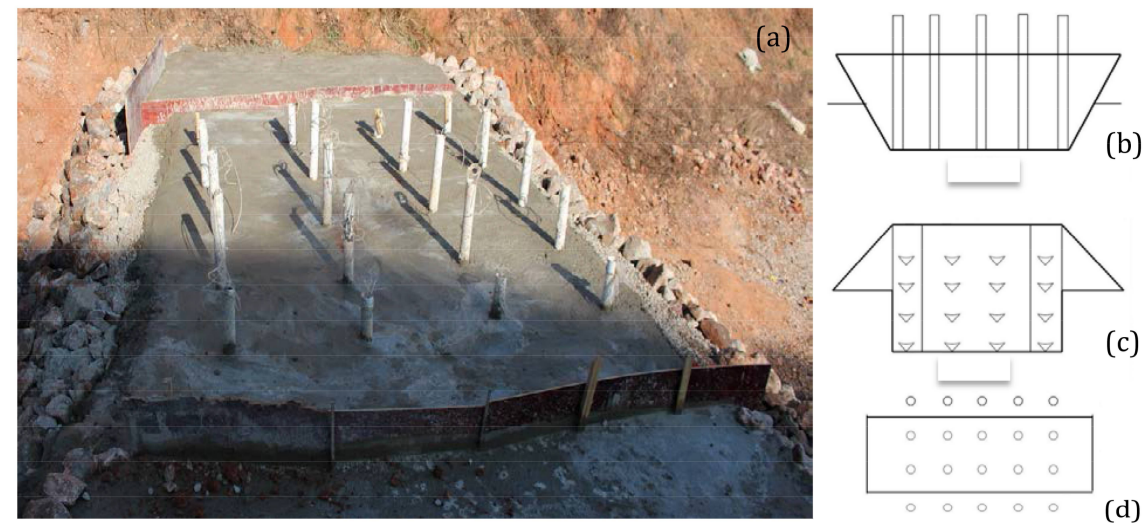

(c)

(d)

Figure 3. Photo after the installation of the PRW (a). The front (b); side (c); and top (d) view of the PRW. The top was covered with $0.3 \mathrm{~m}$ of concrete to prevent vertical leaching. The left is upstream. Water flows from left to right. The board was later removed. The PWR was in the middle and the front and back portions outside the board were filled with concrete only, thus, no monitoring wells were installed in these portions. Each PVC pipe had 4-5 monitoring wells inside at different depths. 


\subsection{Sampling}

The location had dry season and rainy season The PRW was installed in dry season (January 2016) and duplicated samples were taken during the rainy season of 2016 most of the time after rain from the wells that had water using peristaltic pumps. After samples were taken, the wells were pumped dry until refilled with another round of rain. The samples were then transported into the Kunming University of Science and Technology for water chemistry and contaminant analyses.

\subsection{Chemical Analyses}

For batch and column experiments, the As concentration was analyzed using a Millennium System Excalibur (PS Analytical Ltd., Orpington, UK) with a detection limit of $0.1 \mu \mathrm{g} / \mathrm{L}$. For the pilot scale demonstration, As was analyzed using an atomic fluorescence method. Fifty milliliters of samples were filleted and then $5 \mathrm{~mL}$ of nitric acid was added following by digestion and filtration. The samples were further reduced by adding thiourea+ascorbic acid at a concentration of $60 \mathrm{~g} / \mathrm{L}$ followed by dilution with $5 \% \mathrm{HCl}$ before analyses. The instrument used was AF-610D from Beijing Ruili Instrument Co., Beijing, China.

\section{Results and Discussion}

\subsection{The Zeolite Characterization}

The XRD analysis showed that the zeolite was made by $65 \%$ clinoptilolite and $27 \%$ stibnite (Figure 4). The cation exchange capacity (CEC) value of the zeolite was $890 \mathrm{mmol} / \mathrm{kg}$, while the external CEC (ECEC) was $100 \mathrm{mmol} / \mathrm{kg}$. These values provide a foundation for its modification by ionic liquids (IL). Normally, the loading of IL on zeolite should be at $200 \%$ of the ECEC value.

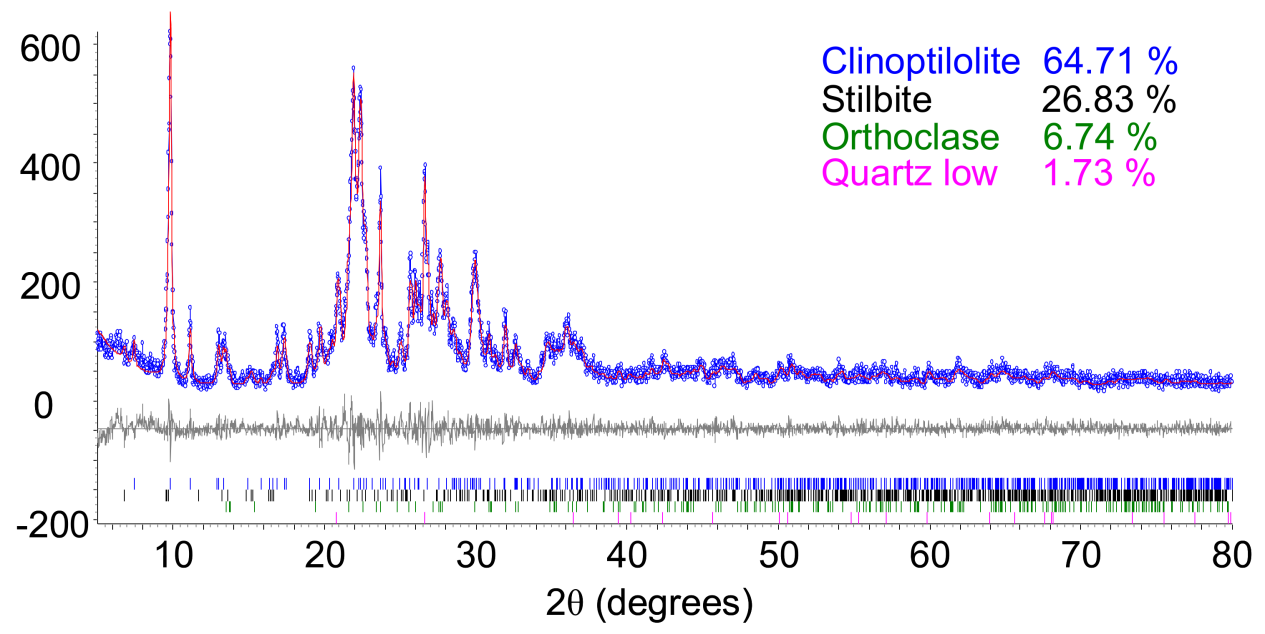

Figure 4. XRD patterns of the raw zeolite showing nice match (black curve around $y=0$ ) between the observed (pint curve) and fitted (blue circles) data. The vertical lines above the $x$-axis are for the reflections of the four mentioned minerals.

\subsection{Batch Results on As Removal}

The As sorption capacities on ILMZ were 11 and $17 \mathrm{mmol} / \mathrm{kg}$ for particles of $0.35-1.0 \mathrm{~mm}$ and 1.0-1.41 $\mathrm{mm}$ ranges, respectively (Figure $5 \mathrm{a}$ ). These values are much larger than $6-8 \mathrm{mg} / \mathrm{kg}$ sorption of $\mathrm{As}(\mathrm{III})$ and $\mathrm{As}(\mathrm{V})$ on Fe-exchanged zeolite [14]. In comparison, the ECEC values of the zeolite of these two particle size ranges were 25 and $40 \mathrm{mmol} / \mathrm{kg}$. The As uptake increase with from $\mathrm{pH} 1$ to $\mathrm{pH} \mathrm{6,above} \mathrm{which} \mathrm{the} \mathrm{change} \mathrm{in} \mathrm{As} \mathrm{sorption} \mathrm{was} \mathrm{minute} \mathrm{(Figure} \mathrm{5b).} \mathrm{The} \mathrm{pH}$ of the water in the contaminated area was about 5-6. Thus, it was anticipated that the ILMZ could achieve its best As 
removal efficiencies. Kinetic study showed that As removal involved in two stages with the first stage almost instantaneous (Figure 5c). At this stage, the amount of As uptake was about 50\% of the As uptake at $24 \mathrm{~h}$. More counterion $\mathrm{Cl}$ was removed as As sorption on ILMZ (Figure 5d), suggesting that surface anion exchange was responsible for the uptake of As. More $\mathrm{Cl}$ desorbed due to initial admicelle formation of IL [15]. Although the stability of IL on zeolite was not evaluated, the long-term stability of HDTMA on zeolite against different $\mathrm{pH}$, ionic strengths, and biological activities was confirmed in a batch study [16].
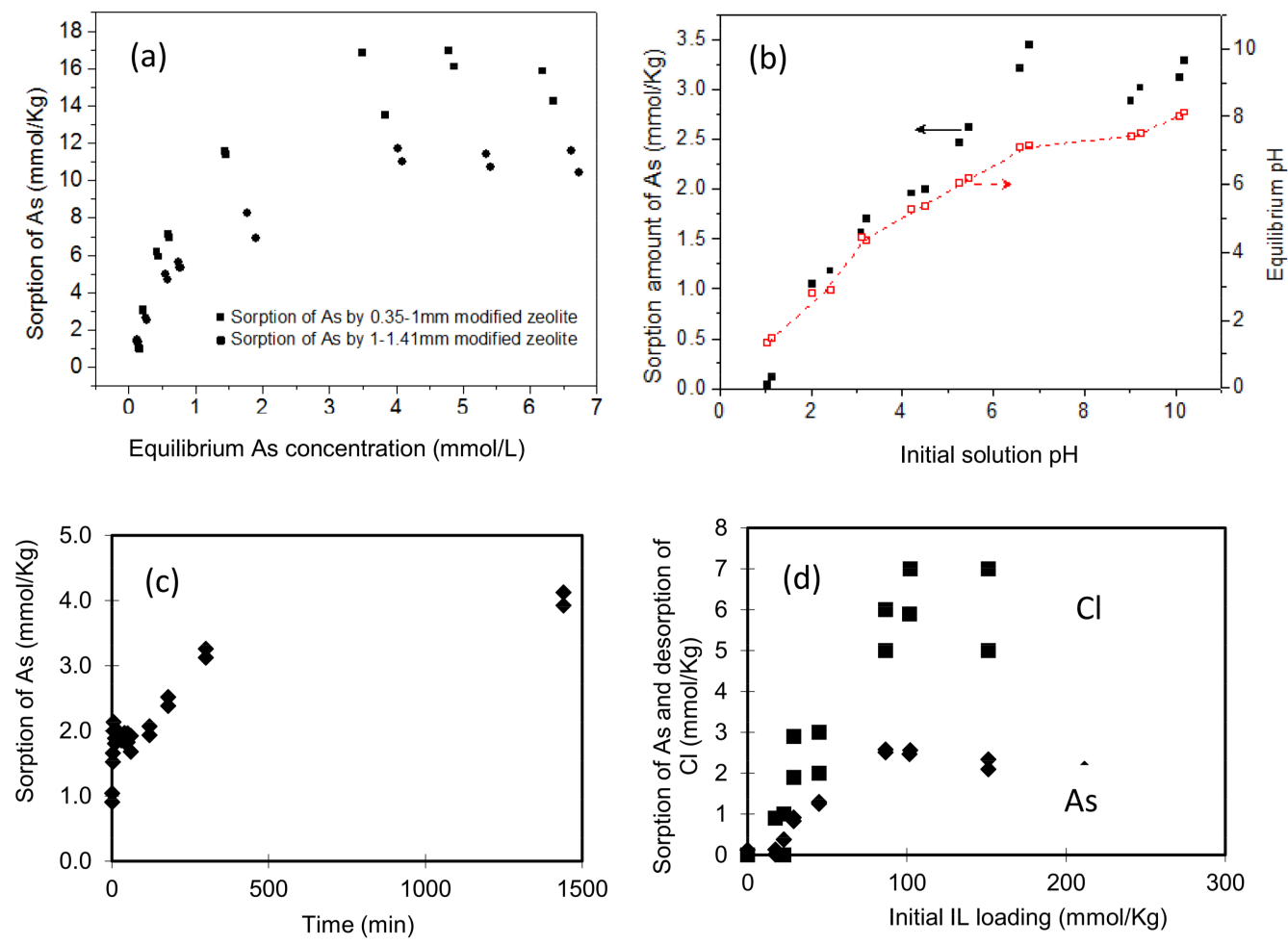

Figure 5. Arsenic sorption isotherm on ILMZ of different particle sizes (a); as a function of initial $\mathrm{pH}$ (solid symbols with left $Y$-axis) and equilibrium solution $\mathrm{pH}$ (open symbols with right $Y$-axis) (b); and affected by contact time (c); and the effect of initial IL loading on As ( $)$ sorption and counterion $\mathrm{Cl}$ desorption (d).

\subsection{Column Results on As Removal}

Transports of As through raw and ILMZ columns were demonstrated in Figure 6. The retardation factor, defined as the number of pore volumes (PVs) when the effluent concentration was equal to $50 \%$ of the input concentration, was 1 for the raw zeolite, showing zero As retardation. In contrast, the retardation factor was 30 and 57 for ILMZ with particle sizes of 0.35-1.0 and 1.0-1.41 mm ranges (Figure 6). The time for effluent concentration to reach the input concentration was 120 to $250 \mathrm{~h}$, in comparison to 70 to $210 \mathrm{~h}$ when bismuth impregnated aluminum oxide was used for As removal [17]. The number of PVs to reach full breakthrough was 32 and 80 in this study, while the PV was 15 and 35 for As transport through columns packed with cross-linked macroporous polymer impregnated with hydrous iron oxide [18]. The total output volume with an effluent As concentration less than $10 \mathrm{ppb}$ was about 450-550 mL. These values correspond to treating 450-550 t of As contaminated water at an initial concentration of $900 \mathrm{ppb}$ per ton of ILMZ. 

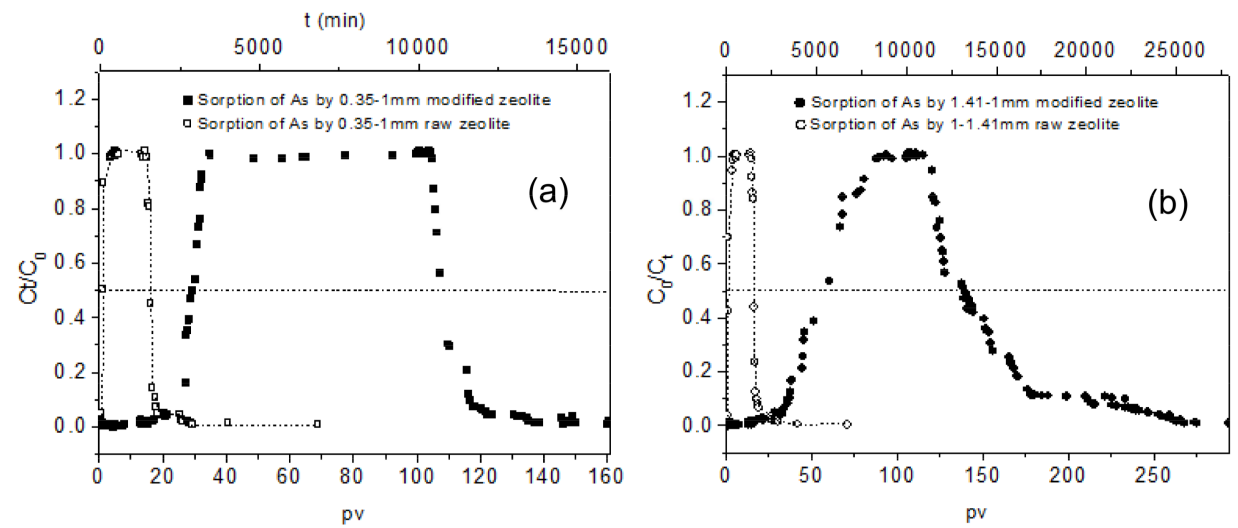

Figure 6. Arsenic transport through zeolite and ILMZ of different particle sizes. (a) 0.35-1.0 mm ranges; (b) $1.0-1.41 \mathrm{~mm}$ ranges.

\subsection{Pilot Tests on As Transport through PRW}

The special and temporal As concentration profiles in the PRW are illustrated in Figure 7.

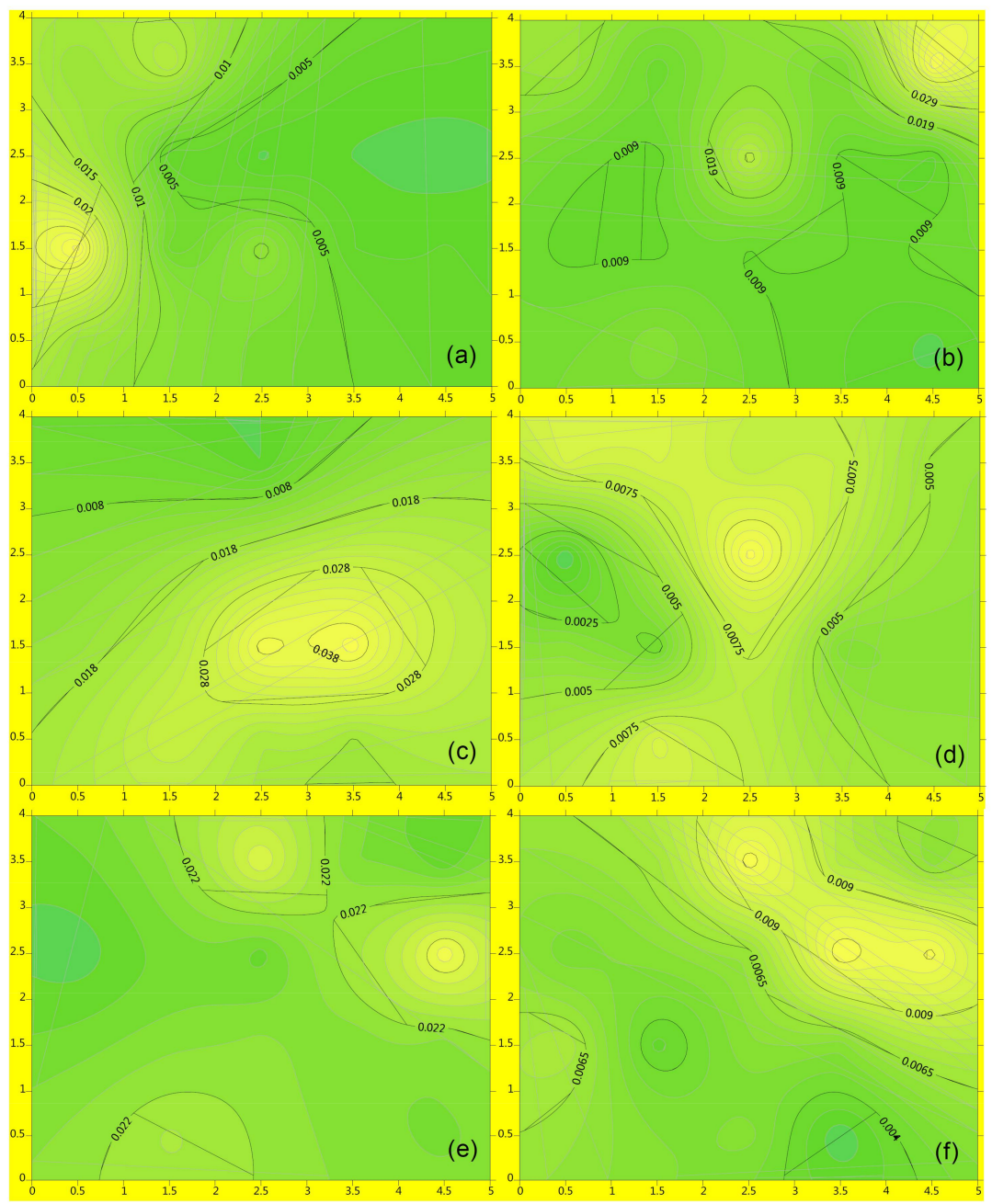

Figure 7. As concentration across the PRW sampled from 4/20/16 (a); 5/25/16 (b); 6/17/16 (c); 7/11/16 (d); 8/5/16 (e); and 10/19/16 (f). The location of wells was plotted in Figure 3. The flow direction is from the bottom, up. The units of values in the $x$ - and $y$-axes are meters. The unit for the contour lines is $\mathrm{mg} / \mathrm{L}$ of As. 
At the $0.5 \mathrm{~m}$ above the base of the PRW, the As concentration remained constant over the six month period. The highest As concentration was still below $0.05 \mathrm{mg} / \mathrm{L}$. The average As concentration at the upper stream of the PRW was $0.14 \mathrm{mg} / \mathrm{L}$, while the average As concentration after passing through the PRW was $0.004 \mathrm{mg} / \mathrm{L}$, with a removal of $96 \%$ in May 2016. Similarly the average As concentration at the upper stream of the PRW was $0.14 \mathrm{mg} / \mathrm{L}$, while the average As concentration after passing through the PRW was $0.01 \mathrm{mg} / \mathrm{L}$, a removal of $92 \%$ in June. In July, the average As concentration at the upper stream of the PRW was $0.19 \mathrm{mg} / \mathrm{L}$, while the average As concentration after passing through the PRW was $0.001 \mathrm{mg} / \mathrm{L}$, with a removal of $99 \%$. In August, the average As concentration at the upper stream of the PRW was $0.51 \mathrm{mg} / \mathrm{L}$, while the average As concentration after passing through the PRW was $0.02 \mathrm{mg} / \mathrm{L}$, corresponding to a removal of $96 \%$. Overall, the As removal rate was $96 \%$. As there are no similar PRWs for the removal of As for comparison, data for the removal of other contaminants by PRWs were briefly compared. A pilot scale PRW installed in an industrial facility in New York in 1995 and the data from two years of monitoring revealed that the degradation rated of volatile organic carbon contents were similar to those obtained from laboratory results [19]. Significant removal of heavy metals was observed for a pilot-scale PRW installed in British Columbia, Canada over a 21-month period [20]. Pilot tests using surfactant-modified zeolite as PRW materials also showed great $\mathrm{Cr}(\mathrm{VI})$ and perchloroethyene (PCE) removal in 41 days with a retardation factor of 42 and 29 for $\mathrm{Cr}(\mathrm{VI})$ and PCE [15]. This study, although preliminary, also provided data for its PWR performance over a six-month period. Thus, results confirmed that PRW technologies not only provide remedial processes for underground water, but are also applicable for the treatment of surface channel water.

\section{Conclusions}

This study was the first to demonstrate using ionic liquid modified zeolite as a permeable reactive wall (PRW) to intercept and remediate surface water contaminated by arsenic (As) at the pilot-scale. Batch studies revealed an As uptake capacity of about $15 \mathrm{mmol} / \mathrm{kg}$. Column studies showed an As retardation factor of 30 to 50 . The preliminary data from the pilot study showed that pilot test results agreed with the prediction made in batch and column tests and demonstrated that the PRW can also achieve remediation goals under above-surface condition to treat seasonal surface water.

Acknowledgments: The funding from Ministry of Science and Technology of China under the grant no. 2014DFA91000 and Fundamental Research Funds for the Central Universities (2652017366) are greatly appreciated.

Author Contributions: L.L. and Z.L. conceived and designed the experiments; Z.L. and Y.W. installed the PRW; G.L. and L.M. participated the experiments; X.W. and S.S. conducted the batch and column experiments. X.W. and Y.W. analyzed the data; P.N. supervised the whole project; S.S., Y.W., and Y.W. processed the field data; Z.L. drafted the manuscript paper. All co-authors read and approved the final manuscript.

Conflicts of Interest: The authors declare no conflict of interest.

\section{References}

1. Bowman, R.S.; Li, Z.; Roy, S.J.; Burt, T.; Johnson, T.L.; Johnson, R.L. Pilot Test of a Surfactant-Modified Zeolite Permeable Barrier for Groundwater Remediation. In Physicochemical Groundwater Remediation; Smith, J.A., Burns, S., Eds.; Kluwer Academic Publishers: Norwell, MA, USA, 2001; pp. 161-185.

2. Wilkin, R.T.; Acree, S.D.; Ross, R.R.; Beak, D.G.; Lee, T.R. Performance of a zerovalent iron reactive barrier for the treatment of arsenic in groundwater: Part 1. Hydrogeochemical studies. J. Contam. Hydrol. 2009, 106, 1-14. [CrossRef] [PubMed]

3. Richards, P. Seven-year performance evaluation of a permeable reactive barrier. Remediat. J. 2008, 18, 63-78. [CrossRef] 
4. U.S. Department of Energy. Performance Assessment and Recommendations for Rejuvenation of a Permeable Reactive Barrier: Cotter Corporation's Canon City, Colorado, Uranium Mill; U.S. Department of Energy: Grand Junction, CO, USA, 2005. Available online: https://www.energy.gov/sites/prod/files/canon_city_prb.pdf (accessed on 5 April 2018).

5. Bi, J.; Liu, C.; Li, S. Variation of water quality of Yangzonghai Lake affected by arsenic pollution. Water Resour. Prot. 2014, 30, 84-89, (In Chinese with English Abstract).

6. Wang, Z.; He, B.; Pan, X.; Zhang, K.; Wang, C.; Sun, J.; Yun, Z.; Jiang, G. The levels, trends and risk assessment of arsenic pollution in Yangzonghai Lake, Yunnan. Sci. Sin. Chim. 2011, 41, 556-564. [CrossRef]

7. Zhang, Y.; Yun, X.; Zhang, Y.; Chen, X.; Liu, J.; Wang, J.; Zhang, Y.; Sun, C. Distribution and sources of arsenic in Yangzonghai Lake, China. Environ. Sci. 2012, 33, 3768-3777. (In Chinese with English Abstract)

8. Chen, J.; Zhang, S.; Yang, X.; Huang, Z.; Wang, S.; Wang, C.; Wei, Y.; Zhang, G.; Xiao, J. Arsenic removal by coagulation process and the field expanding experiments for Yangzonghai Lake. Environ. Sci. 2015. 36, 202-208, (In Chinese with English Abstract)

9. Chen, J.; Wang, S.; Zhang, S.; Yang, X.; Huang, Z.; Wang, C.; Wei, Q.; Zhang, G.; Xiao, J.; Jiang, F.; et al. Arsenic pollution and its treatment in Yangzonghai lake in China: In situ remediation. Ecotoxicol. Environ. Saf. 2015, 122, 178-185. [CrossRef] [PubMed]

10. Liu, R.; Yang, C.; Li, S.; Sun, P.; Shen, S.; Li, Z. Arsenic mobility in the arsenic-contaminated Yangzonghai Lake in China. Ecotoxicol. Environ. Saf. 2014, 107, 321-327. [CrossRef] [PubMed]

11. Puls, R.W.; Paul, C.J.; Powell, R.M. The application of in situ permeable reactive (zero-valent iron) barrier technology for the remediation of chromate-contaminated groundwater: a field test. Appl. Geochem. 1999, 14, 989-1000. [CrossRef]

12. Benner, S.G.; Blowes, D.W.; Ptacek, C.J. A full-scale porous reactive wall for prevention of acid mine drainage. Groundw. Monit. Remediat. 1997, 17, 99-107. [CrossRef]

13. Weihermüller, L.; Siemens, J.; Deurer, M.; Knoblauch, S.; Rupp, H.; Göttlein, A.; Pütz, T. In situ soil water extraction: A review. J. Environ. Qual. 2007, 36, 1735-1748. [CrossRef] [PubMed]

14. Li, Z.; Jean, J.S.; Jiang, W.T.; Chang, P.H.; Chen, C.J.; Liao, L. Removal of arsenic from water using Fe-exchanged natural zeolite. J. Hazard. Mater. 2011, 187, 318-323. [CrossRef] [PubMed]

15. Bowman, R.S. Applications of surfactant-modified zeolites to environmental remediation. Microporous Mesoporous Mater. 2003, 61, 43-56. [CrossRef]

16. Li, Z.; Roy, S.J.; Zou, Y.; Bowman, R.S. Long term chemical and biological stability of surfactant-modified zeolite. Environ. Sci. Technol. 1998, 32, 2628-2632. [CrossRef]

17. Zhu, N.; Qiao, J.; Ye, Y.; Yan, T. Synthesis of mesoporous bismuth-impregnated aluminum oxide for arsenic removal: Adsorption mechanism study and application to a lab-scale column. J. Environ. Manag. 2018, 211, 73-82. [CrossRef] [PubMed]

18. Taleb, K.; Markovski, J.; Milosavljević, M.; Marinović-Cincović, M.; Rusmirović, J.; Ristić, M.; Marinković, A. Efficient arsenic removal by cross-linked macroporous polymer impregnated with hydrous iron oxide: Material performance. Chem. Eng. J. 2015, 279, 66-78. [CrossRef]

19. Vogan, J.L.; Focht, R.M.; Clark, D.K.; Graham, S.L. Performance evaluation of a permeable reactive barrier for remediation of dissolved chlorinated solvents in groundwater. J. Hazard. Mater. 1999, 68, 97-108. [CrossRef]

20. Ludwig, R.D.; McGregor, R.G.; Blowes, D.W.; Benner, S.G.; Mountjoy, K. A permeable reactive barrier for treatment of heavy metals. Groundwater 2002, 40, 59-66. [CrossRef]

(C) 2018 by the authors. Licensee MDPI, Basel, Switzerland. This article is an open access article distributed under the terms and conditions of the Creative Commons Attribution (CC BY) license (http://creativecommons.org/licenses/by/4.0/). 